\title{
AS CLÁUSULAS DE NÃO COMPETIÇÃO NOS CONTRATOS EMPRESARIAIS DE LONGA DURAÇÃO
}

\author{
Rodrigo Rentzsch Sarmento Barata ${ }^{1}$ \\ Daniel Marques Raupp ${ }^{2}$
}

Resumo: O objetivo deste artigo é tratar das restrições contratuais à concorrência, principalmente no tocante à cláusula de não competição. Primeiramente tratar-se-á dos aspectos gerais das referidas cláusulas, principalmente no que toca às suas repercussões dogmáticas, com destaque para a boa fé objetiva, a função social e a sua interpretação. Abordar-se-á, também, os requisitos dessas cláusulas reconhecidos pela doutrina e pela jurisprudência, como a exigência de um interesse legítimo a ser protegido, a necessidade de definição de limites materiais, temporais e espaciais. Por fim, analisar-se-á os aspectos da eficácia da não competição.

Palavras-chave: Contrato. Competição. Boa-fé. Interpretação. Longa duração.

\section{THE NON-COMPETE CLAUSES IN LONG-TERM CORPORATE CONTRACTS}

Abstract: This paper will analyze the contractual restrictions on competition, especially with regard to the non-compete clause. Firstly, we will analyze the general aspects of these clauses, in particular their dogmatic repercussions, mainly in regards to the good faith, their social function and the interpretation of theses clauses. The paper will also analyze the legal requirements of the non-compete as recognized by the doctrine and the case law, such as the requirement of legitimate interest and the necessity to define material, temporal and spatial limits. Finally, aspects of the effectiveness of non-compete will be analyzed.

Keywords: Contract. Competition. Good-faith. Interpretation. Long-term.

\section{INTRODUÇÃO}

O objetivo deste artigo é apresentar os delineamentos dogmáticos das cláusulas de não competição (também conhecidas como cláusulas de non-compete, de não concorrência ou, ainda de não reestabelecimento), nos contratos empresarias de longa duração. Trata-se de modelo jurídico ${ }^{3}$ bastante conhecido e utilizado, principalmente em mercados com grau

\footnotetext{
${ }^{1}$ Mestrando em Direito Empresarial pela Universidade Federal do Rio Grande do Sul (UFRGS). Advogado.

${ }^{2}$ Mestrando em Direito Empresarial pela Universidade Federal do Rio Grande do Sul (UFRGS). Advogado

3 "Modelos são estruturas normativas dinâmicas, que integram fatos e valores em normas jurídicas.

Correspondem às fontes, mas dela se desprendem por se apresentarem no devir da mutável experiência jurídico-social: há modelos legislativos, jurisprudências, costumeiros e negociais, os quatro consubstanciando a categoria dos modelos jurídicos" (MARTINS-COSTA, 2014, p.10).
}

Revista Brasileira de Direito Empresarial | e-ISSN: 2526-0235| Porto Alegre | v. 4 | n. 2 | 
acentuado de desenvolvimento tecnológico, onde o conhecimento desempenha papel tão, ou mais, relevante que a propriedade do capital. Essencialmente, tais cláusulas estabelecem uma restrição na concorrência entre os contratantes, sendo comum nos contratos de longa duração (como franchising e distribuição) e nos contratos que envolvem sociedades comerciais e seu patrimônio, comumente trespasse de estabelecimento e fusões e aquisições ${ }^{4}$.

O ordenamento jurídico brasileiro carece de sistematização do tema, o que se revela um problema na medida em que a inserção das cláusulas de não competição em contratos empresariais já é prática corrente de um ambiente negocial brasileiro maduro e sofisticado, além de bastante internacionalizado. O método utilizado para tratar do tema é essencialmente dogmático, utilizando-se de fontes doutrinárias e jurisprudenciais para tratar do objeto da pesquisa.

Assim, busca-se, em um primeiro momento, analisar os fundamentos subjacentes às cláusulas de não competição, bem como os elementos para sua interpretação. Em seguida, aborda-se a incidência da boa-fé objetiva nos contratos empresariais duradouros, como formadora de um dever de não competir, em razão da própria natureza do contrato, e, ao final, os requisitos de validade e de eficácia da cláusula, além da análise dos efeitos enquanto dever oriundo da boa-fé objetiva e como obrigação contratual expressamente pactuada.

\section{ASPECTOS GERAIS DAS CLÁUSULAS DE NÃO COMPETIÇÃO}

Nas relações contratuais a cláusula de não competição pode ser caracterizada como uma obrigação especificamente prevista na $1 \mathrm{ei}^{5}$ ou em contrato, cujos requisitos e limites constituem tema de fundamental importância para a boa compreensão desse modelo jurídico.

\footnotetext{
4 "Por meio dela, aquele que aliena fica proibido de oferecer concorrência ao comprador, por determinado período de tempo e/ou em certo mercado. Restringe-se, por vontade das partes, a concorrência entre o vendedor e o comprador, reduzindo-se o risco de retorno não satisfatório do investimento. A justificativa é viabilizar a transferência para o novo proprietário da efetiva capacidade de gerar lucros da organização" (FORGIONI, 2018, pp. 287-288).

${ }^{5}$ Conhecida obrigação legal de não competição é aquela referente ao trespasse de estabelecimento, prevista no art. 1.147 do Código Civil: "Não havendo autorização expressa, o alienante do estabelecimento não pode fazer concorrência ao adquirente, nos cinco anos subseqüentes à transferência. Parágrafo único. No caso de arrendamento ou usufruto do estabelecimento, a proibição prevista neste artigo persistirá durante o prazo do contrato".
}

Revista Brasileira de Direito Empresarial | e-ISSN: 2526-0235| Porto Alegre | v. 4 | n. 2 |

p. $20-38$ | Jul/Dez. 2018 
Pode-se também entender que a não competição é um dever anexo independente decorrente da boa-fé objetiva.

Quanto à sua natureza jurídica, trata-se, em breve síntese, de uma obrigação de não fazer. Consiste, portanto, em uma prestação negativa, isto é, em uma conduta omissiva. Como destaca Orlando Gomes (2000), este tipo de prestação pode ter como objeto abstenções economicamente importantes, como é o caso da proibição de concorrência.

\subsection{Delineamentos dogmáticos das cláusulas de não competição nos contratos de longa duração}

Como já referido, a cláusula de não competição possui grande relevância em mercados tecnologicamente avançados, onde determinadas hipóteses de concorrência podem ser consideradas desleais em função do conhecimento do negócio que um dos contraentes obteve durante o contrato. Esse modelo jurídico de não competição surge a partir da revolução industrial da Inglaterra, por meio dos usos e costumes, espalhando-se, em seguida, pelas economias e sistemas jurídicos mais avançados, como o suíço, francês, italiano e alemão (WALD; XAVIER, 2010).

A cláusula de não competição é bastante utilizada em contratos de longa duração ${ }^{6}$ como os contratos de distribuição ${ }^{7}$ e os contratos de franquia ${ }^{8}$. Trata-se de instrumento que exerce a função de proteção da concorrência leal entre contratantes que manterão relação contratual, protegendo, direta ou indiretamente, a clientela e o fundo de comércio daquele contratante que compartilhou ou transferiu informações e know how (PIRAJÁ; CANESIN, 2015) forneceu produtos e permitiu que o outro contratante desenvolvesse atividade lucrativa e angariasse clientela.

\footnotetext{
${ }^{6}$ Para Giorgio Oppo (1943), nos contratos de longa duração, o tempo se apresenta como elemento individualizante da prestação. É característica desses contratos que a obrigação somente se extingue com o decurso do tempo. A relação jurídica se renova com o contínuo adimplemento e o tempo é elemento essencial para que o contrato cumpra sua função econômica.

7 Paula Forgioni define o contrato de distribuição como "contrato bilateral, sinalagmático, atípico e misto, de longa duração [...]". (2008, p. 116).

${ }^{8}$ Lei $8.955 / 94$. Art. $3^{\circ}$ Sempre que o franqueador tiver interesse na implantação de sistema de franquia empresarial, deverá fornecer ao interessado em tornar-se franqueado uma circular de oferta de franquia, por escrito e em linguagem clara e acessível, contendo obrigatoriamente as seguintes informações: [...]

XIV - situação do franqueado, após a expiração do contrato de franquia, em relação a:

b) implantação de atividade concorrente da atividade do franqueador;
}

Revista Brasileira de Direito Empresarial | e-ISSN: 2526-0235| Porto Alegre | v. 4 | n. 2 |

p. $20-38$ | Jul/Dez. 2018 
Importa, ainda, salientar que as cláusulas de não competição importam em redução voluntária de determinados direitos fundamentais da ordem econômica, quais sejam, a livre iniciativa (art. $1^{\circ}$, IV e art. 170, caput, da Constituição Federal) e a livre concorrência (art. 170, IV, da Constituição Federal). Conforme Paula Forgioni, tal restrição é lícita, isto é, “os negócios privados empresarias podem estabelecer limitações voluntárias à sua própria liberdade" (2018, p. 283). Nesse contexto, os contratos empresariais apresentam, dentro de seus objetivos, a necessidade de viabilizar a contenção futura da conduta dos agentes econômicos. Para estabelecer tais contenções, é possível que as empresas, ou outros agentes econômicos, limitem sua liberdade, vinculando-se, pelo contrato, a compromissos de vedação de determinadas práticas futuras. Sendo os contratos essenciais à coesão social e à economia de mercado, essa autocontenção futura de determinado ato de concorrência é fortemente protegida pelo ordenamento jurídico (FORGIONI, 2018).

\subsection{Diferenciação entre a cláusula de não competição e outros tipos obrigacionais}

Como já referido, as cláusulas de não competição são mecanismos contratuais comumente utilizados em contratos empresariais de longa duração. Note-se que apesar de ser uma cláusula comum nesses tipos de contrato, há outros tipos obrigacionais que exercem funções semelhantes na prática corrente de alguns mercados, principalmente no que tange aos contratos de shopping center, representação comercial e distribuição. Diante disso, mostra-se necessário fazermos algumas diferenciações para melhor compreender a estrutura do noncompete.

Primeiramente, deve-se diferenciar o non-compete da cláusula de raio. Estas últimas são típicas dos contratos de shopping center. Trata-se de uma cláusula que impede que o lojista implemente outro estabelecimento em determinado espaço territorial no entorno do shopping center, de forma a preservar o mercado criado por essa instituição e sua composição de estabelecimentos. Para Alexandre David Santos, referindo-se especificamente à hipótese dos contratos de franquia "[E]nquanto a cláusula de raio tem por finalidade proteger o mix comercial do shopping center, por meio de cláusula específica em contrato de locação, a cláusula de não concorrência prevista em contrato de franquia visa a proteger o know-how do franqueador transmitido ao franqueado" (2016, p. 33).

Revista Brasileira de Direito Empresarial | e-ISSN: 2526-0235| Porto Alegre | v. 4 | n. 2 |

p. $20-38$ | Jul/Dez. 2018 
Em segundo lugar, é importante diferenciar o non-compete das cláusulas de exclusividade. Estas são típicas dos mais variados contratos empresariais de longa duração, mas principalmente em contratos de distribuição e representação comercial, onde o fornecedor irá proteger determinado mercado para que o distribuidor atue e, em contrapartida, o representante ou distribuidor poderá negociar exclusivamente com aquele fornecedor no mercado em que ambos atuem. Assume uma pluralidade de significados, mas geralmente "estabelece a proibição de a parte realizar negócios com terceiros, tornando-se 'exclusiva' da outra, por certo período" (FORGIONI, 2018, p. 286).

A exclusividade estabelecida entre as partes acarreta uma redução da liberdade dos agentes econômicos e também de terceiros, que não poderão mais contratar com aquele agente econômico. As cláusulas de exclusividade são consideradas exemplos de restrição vertical, ou seja, de restrição posta à concorrência e à liberdade de iniciativa. É, em síntese, uma autocontenção da liberdade econômica por parte daquele que se vincula a somente comerciar com outro. Isso impacta diretamente o campo de atuação de agentes econômicos externos a essa relação (FORGIONI, 2018).

Não há prejuízo, ainda, que as partes venham a estabelecer cláusulas das mais variadas, determinando vedações de determinadas práticas de concorrência no decorrer de todas as fases contratuais, inclusive na fase pré-contratual (como é o caso de cláusulas de exclusividade de negociação em contratos preliminares), durante a performance do contrato (como é o caso das cláusulas de exclusividade e de raio) e na fase pós-contratual (como é o caso do non-compete). A própria cláusula de não competição apresenta uma morfologia variada, a depender do tipo de contrato e das pessoas envolvidas ${ }^{9}$.

No entanto, analisando-se essas cláusulas de não competição em contraposição aos demais tipos de cláusulas, nota-se que a cláusula de não competição (i) tem eficácia essencialmente pós-contratual e (ii) tem escopo temporal, geográfico e mercadológicos determinados.

\subsection{Interpretação das cláusulas de não competição}

\footnotetext{
9 "Há vários tipos de cláusulas de non compete. Naquela mais usual, ajusta-se que certas pessoas físicas [antigos controladores e diretores da empresa vendida, por exemplo] não se lançarão em negócio semelhante ao alienado. Em outras, as pessoas jurídicas estão envolvidas, colocando-se a restrição sobre a atividade de sociedade e/ou de empresas ligadas. Trata-se de prática absolutamente disseminada, em que as partes estipulam cláusula expressão no instrumento do contrato, ajustando a restrição.” (FORGIONI, 2018, p.288).
}

Revista Brasileira de Direito Empresarial | e-ISSN: 2526-0235| Porto Alegre | v. 4 | n. 2 |

p. $20-38$ | Jul/Dez. 2018 
A existência do non-compete, seja como obrigação ou como dever anexo, decorre do exercício da autonomia privada dos contratantes. Como ressalta Paula Forgioni (2018), a autonomia privada é viga mestra do sistema contratual, permitindo que os contratantes estabeleçam as formas contratuais que melhor se adaptem a sua realidade negocial. Nesse contexto, é possível a inclusão de cláusulas que restrinjam determinados direitos inerentes aos contratantes, dentre elas exatamente o direito de livre iniciativa econômica, que é objeto do non-compete.

Note-se, no entanto, que as partes não contratam pelo mero prazer de trocar declarações de vontade. Ao firmar determinado contratos, os agentes econômicos têm em vista determinado objetivo, que se mescla com a função que esperam o negócio desempenhe. Assim, todo negócio possui uma função econômica (FORGIONI, 2018). E essa função econômica do negócio mostra-se essencial para sua correta compreensão, pois liga-se a uma perspectiva objetiva de circulação dos bens e dos serviços e não a aspectos subjetivos das partes. Tendo em vista que os contratos empresariais sempre estão ligados a objetivos de ganho econômico, é necessário compreendê-los em consonância com a necessidade econômica que buscam objetivamente satisfazer, isto é, em consonância com a sua função econômica (FORGIONI, 2018).

Essa ideia da função econômica dos contratos é de peculiar importância no que toca à interpretação das cláusulas de não competição. O estabelecimento da relação entre função econômica e interpretação reveste a interpretação contratual de juízo de coerência e previsibilidade que viabiliza e incrementa o funcionamento do sistema (FORGIONI, 2018).

Por fim, vale salientar que às cláusulas de não competição se submetem ao imperativo interpretativo delineado no art. 114 do Código Civil ${ }^{10}$, que estabelece uma necessidade de interpretação restritiva aos negócios jurídicos benéficos e à renúncia.

Toda a renúncia de direito deve ser tratada com cautela, tendo em vista que tocam em restrições a determinados direitos fundamentais de ordem econômica assegurados constitucionalmente. Nessas hipóteses de direitos garantidos pela Constituição Federal aos agentes econômicos, como são os casos dos direitos de livre iniciativa e da livre concorrência,

\footnotetext{
${ }^{10}$ Art. 114. Os negócios jurídicos benéficos e a renúncia interpretam-se estritamente.
} 
como as liberdades econômicas, as cláusulas contratuais limitativas da livre atividade econômica, que de alguma forma restringem o âmbito de atuação do empresário, assim como as cláusulas que acarretam uma limitação à livre concorrência, necessitam de interpretação restritiva, abrangendo o menor número de situações possíveis. Como exemplo de interpretação restritiva, se determinado agente econômico voluntariamente renuncia a determinada contraprestação a que teria direito por vínculo contratual, essa renúncia não poderá abranger algo não incluído no ato original (FORGIONI, 2018).

\subsection{Boa-fé objetiva e dever de não competição}

No âmbito dos contratos empresariais, a boa-fé objetiva tem peculiar importância. A boa-fé é máxima objetiva que determina o incremento de deveres aos contratantes, para além daqueles que o seu contrato constitui. Ela é endereçada a todos os partícipes do vínculo obrigacional e pode, inclusive, criar deveres para o credor, o qual, tradicionalmente, é apenas considerado titular de direitos (COUTO E SILVA, 2006). Especialmente para o direito comercial, agir de acordo com a boa-fé objetiva significa "adotar o comportamento jurídica e normalmente esperado dos 'comerciantes cordatos', dos agentes econômicos ativos e probos em determinado mercado [ou 'em certo ambiente institucional'], sempre de acordo com o direito” (FORGIONI, 2018, p. 122).

A boa-fé objetiva nos contratos empresariais acarreta que ao longo do processo obrigacional determinados atos secundários sejam realizados para o correto adimplemento da obrigação principal. Tratam-se de deveres anexos, que comportam tratamento durante a totalidade da relação jurídica. Esses deveres podem ser examinados durante o desenvolvimento da relação, e, mesmo, em momento posterior ao adimplemento da obrigação principal. Os deveres anexos se revelam em diversas condutas dos contratantes como em “indicações, atos de proteção, como o dever de afastar danos, atos de vigilância, de guarda, de cooperação, de assistência" (COUTO E SILVA, 2006, p. 93).

Alguns desses deveres anexos nascem do próprio contrato, mas outro surgem desvinculados da vontade originária núcleo do negócio jurídico, por vezes possuindo vida autônoma. Os deveres dessa categoria são chamados de independentes, pois podem perdurar mesmo depois de adimplida a obrigação principal (COUTO E SILVA, 2006).

Revista Brasileira de Direito Empresarial | e-ISSN: 2526-0235| Porto Alegre | v. 4 | n. 2 |

p. $20-38$ | Jul/Dez. 2018 
Podem, esses deveres anexos, ser acionados independentemente da prestação principal. Em virtude de poderem ser acionados sem com isso acarretar o desfazimento da obrigação principal, é que se lhes denominou de deveres anexos independentes. Dependem, contudo, da obrigação principal para seu nascimento, podendo, porém, como já se mencionou, perdurar ainda depois do cumprimento daquela. Conforme Clóvis do Couto e Silva (2006, pp96-97):

[E]ntre os deveres que permanecem mesmo depois da execução da relação principal, pode ser mencionado o dever do sócio, que se retira de uma sociedade, de não prejudicar o funcionamento da sociedade de que participou, revelando circunstância que só podia conhecer em razão de sua qualidade de sócio. Outro exemplo é o dever de empregado que, nessa qualidade, tomou conhecimento de alguma circunstância relevante, como um segredo de fabricação, de não leva-lo ao conhecimento, por exemplo, de uma firma concorrente, mesmo depois de haver sido despedido.

Nota-se, portanto, que a não competição nos contratos empresariais também pode se revelar um dever anexo independente da obrigação principal, oriundo da incidência da boa-fé objetiva no processo obrigacional.

\section{REQUISITOS DA VALIDAdE E EFICÁCiA DAS CLÁUSULAS DE NÃO COMPETIÇÃO}

Como adverte o autor português Mário Júlio de Almeida Costa (1998, p. 611), "todas as obrigações negativas cerceiam a liberdade do devedor, suscitando-se o problema da sua validade sempre que o façam num grau manifestamente excessivo, em violação de uma regra de ordem pública".

Daí emerge um dos principais problemas enfrentados pela doutrina e pelos Tribunais, relacionado à obrigação de não competir, que diz respeito aos seus requisitos e à necessidade de limites. A funcionalização dos contratos - art. 421 do Código Civil -, como elemento de controle externo, impõe limites à liberdade de contratar $^{11}$, e a boa-fé objetiva opera deveres

${ }^{11}$ Conforme Gerson Luiz Carlos Branco, a "funcionalização implica intervenção no regime dos efeitos para proteção do interesse social". (BRANCO, 2014, p. 268).

Revista Brasileira de Direito Empresarial | e-ISSN: 2526-0235| Porto Alegre | v. 4 | n. 2 |

p. $20-38$ | Jul/Dez. 2018 
entre as partes, que abrangem toda a relação jurídica (COUTO E SILVA, 2006), inclusive a sua formação.

Entretanto, nestes tipos de contratos duradouros, destaca-se a assertiva de Paula Forgioni (2008), que ao esmiuçar dogmaticamente os contratos de distribuição, revelou que muitas vezes caracteriza-se a dependência econômica de uma parte em relação à outra, e a parte dominante pode impor condições contratuais à outra.

A cláusula de não competição é muitas vezes imposta pelo contratante mais forte em contratos de franquia e distribuição, assim, a eficácia dessa previsão contratual deve estar condicionada a certos limites, que vêm sendo enfrentados pela doutrina e pela jurisprudência.

Luiz Gastão Paes de Barros Leães (2004 apud NERY JR., 2014) indicou dois requisitos (que o autor denomina condições essenciais) para que a cláusula em questão seja legalmente permitida. Em primeiro lugar, o citado autor apontou que a cláusula deve (i) corresponder a um interesse legítimo da parte credora da obrigação de não concorrência, via de regra a proteção direta ou indireta de uma clientela e de um fundo de comércio; e, como segunda condição, a previsão (ii) não pode importar na total supressão da liberdade individual da parte devedora, se sujeitando a limites precisos de objeto, de tempo e de espaços.

$\mathrm{O}$ primeiro requisito aproxima-se ao que os autores norte-americanos Jess A. Dance e William W. Sentell (2017), que estudaram a cláusula de não competição no âmbito dos contratos de franquia, chamam de propósitos legítimos que justificariam a restrição de concorrência. Os mencionados autores indicam uma interessante série de propósitos:

(1) Proteger os segredos do negócio e a propriedade das informações do franqueador;

(2) Preservar o fundo de comércio e evitar a confusão entre consumidores;

(3) Garantir a possibilidade de "refranchising", ou seja, instalar nova franquia naquele mercado;

(4) Desencorajar outros franqueados de saírem, protegendo a integridade da rede de franquia.

Os autores Rodrigo Saraiva Porto Garcia e Leonardo da Silva Sant'anna (2017) manifestam, no mesmo viés, que a obrigação de não concorrência deve ser diretamente relacionada com a viabilidade do negócio e ser necessária para evitar o esvaziamento da atividade empresária do estipulante.

Ainda com o mesmo norte, a manifestação do procurador federal Diogo Thomson de Andrade no âmbito de processo do Conselho Administrativo de Defesa Econômica (CADE, 
Ato de Concentração 08012.009679/2007-50) é elucidativa no tocante à necessidade de que a obrigação sirva para proteger legítimos interesses negociais:

As cláusulas de não concorrência são medidas auxiliares ao negócio principal. Como medidas acessórias ao contrato e restritiva de direitos, devem, no entanto, ser efetivamente necessárias para a consecução do objeto contratado. Devem servir, pois, à proteção dos legítimos interesses negociais, de forma a viabilizar o negócio na medida em que confere as condições necessárias para que as partes possam efetivamente apoderar-se de forma integral dos bens tangíveis e intangíveis decorrentes do contrato.

Nota-se, desse efeito, que a existência de um interesse legítimo a ser protegido, relacionado ao negócio (atividade empresária), é considerado um requisito da cláusula de não competição.

Além disso, na opinião de Nelson Nery Júnior (2014), embora incontestável a possibilidade de pactuação das cláusulas de não concorrência, estas não podem ser estabelecidas de forma ilimitada, sem quaisquer restrições.

Nery Júnior cita a posição de Fábio Ulhoa Coelho (1999 apud NERY JR, 2014), para quem a cláusula pode ser contratada desde que preserve a competição futura, não faça referência a todos os segmentos de mercado e não possua tempo e área de incidência indeterminados.

Em outra passagem, Fábio Ulhoa Coelho (2012 apud GARCIA, SANT’ANNA, 2017) ressalta que a validade da cláusula de não concorrência está vinculada ao estabelecimento de limites materiais, limites geográficos e limites temporais.

O limite temporal tem importância amplamente reconhecida, quer seja pela doutrina, quer seja pela jurisprudência. Essa limitação impõe a previsão de um termo final, de modo que a restrição ao exercício da atividade concorrente vigore por um prazo razoável (GARCIA, SANT'ANNA, 2017).

A cláusula não pode impor ao alienante do estabelecimento comercial ou das cotas societárias ou do próprio contrato de trabalho que se abstenha de concorrer com o estabelecimento de que deixa de participar, eternamente, sem prazo delimitado ou com prazo desarrazoado, pois afetaria diretamente o direito de exercer livremente a atividade econômica que bem lhe aprouver (NERY JR, 2014).

Também a respeito deste critério temporal, analisando os casos de contrato de trespasse enfrentados pelo Conselho Administrativo de Defesa Econômica (CADE), Eros

Revista Brasileira de Direito Empresarial | e-ISSN: 2526-0235| Porto Alegre | v. 4 | n. 2 | 
Grau e Paula Forgioni (2005, p. 282), registram que "a regra geral é a de que as cláusulas de não restabelecimento são aceitas desde que limitem a concorrência pelo prazo máximo de cinco anos".

Vera Helena de Mello Franco (2014), ao tratar sobre o contrato de concessão mercantil, reconheceu a possibilidade de pactuação da obrigação de não competição, mediante aplicação do limite temporal da norma do art. 1.147 do Código Civil (cinco anos) e restringindo a limitação à zona de exclusividade delimitada ao concessionário.

No Brasil, não há previsão legal definindo um limite temporal para os efeitos da vedação de competição nos contratos de distribuição, concessão mercantil ou franquia, por exemplo, ao contrário do que se verifica em Portugal, cujo Decreto-Lei $n^{\circ}$ 178/86, que regulamenta o contrato de agência, prevê no art. $9^{\circ 12}$ o possível acordo de não concorrência entre as partes, mas estipula limite temporal de 2 (dois) anos e validade restrita à zona ou círculo de clientes confiado ao agente.

Neste contexto, portanto, o prazo de 5 (cinco) anos previsto no Código Civil (art. 1.147, caput ${ }^{13}$ ) para os contratos de trespasse é utilizado como parâmetro para apreciação da razoabilidade do limite temporal da cláusula de não competição também em outras espécies de contrato.

Outro limite estudado pela doutrina e que encontra guarida na jurisprudência relaciona-se ao aspecto territorial, também chamado de espacial ou geográfico.

Tratando deste limite, Nelson Nery Júnior (2014) defende que a não competição deve restringir-se a área em que poderia, em concreto, haver uma disputa de mercado ou de clientela, ou seja, em áreas em que um dos concorrentes já está estabelecido, de sorte que não seria eficaz uma cláusula vedando a concorrência fora da área geográfica que sofre influência dos contratantes.

A proteção de concorrência pode ser estipulada desde que contenha uma limitação espacial que não ultrapasse o mercado relevante da operação principal objeto do contrato,

12 Artigo 9. ${ }^{\circ}$ Obrigação de não concorrência

1 - Deve constar de documento escrito o acordo pelo qual se estabelece a obrigação de o agente não exercer, após a cessação do contrato, actividades que estejam em concorrência com as da outra parte.

2 - A obrigação de não concorrência só pode ser convencionada por um período máximo de dois anos e circunscreve-se à zona ou ao círculo de clientes confiado ao agente.

${ }^{13}$ Art. 1.147. Não havendo autorização expressa, o alienante do estabelecimento não pode fazer concorrência ao adquirente, nos cinco anos subsequientes à transferência.

Revista Brasileira de Direito Empresarial | e-ISSN: 2526-0235| Porto Alegre | v. 4 | n. 2 |

p. $20-38$ | Jul/Dez. 2018 
podendo se restringir a determinado município, estado, região ou país (NAVAS, 2013, GARCIA; SANT'ANNA, 2017).

Já o chamado limite material relaciona-se à definição do objeto, como lecionam os franceses G. Ripert e R. Roblot (1998 apud FÉRES, 2010), significando uma limitação à abrangência material, que não pode ser desproporcional em relação ao interesse legítimo que se quer proteger.

Sobre este aspecto material, importante registrar que, como a obrigação contratual reflete renúncia a direito de disputar clientela, deve ser interpretada de forma restritiva (em vista da previsão do já citado art. 114 do Código Civil). Nesse sentido, Eros Grau e Paula Forgioni (2005) lembram que é princípio básico do direito que toda interpretação/aplicação de exceção deve ser interpretada/aplicada de forma estreita. Esse princípio já restou afirmado na doutrina francesa (RIPERT; ROBLOT, 2001 apud GRAU, FORGIONI, 2005, p. 293): “La clause de non concurrence s'interprète restrictivement'.

Abordando os requisitos da cláusula de não concorrência em contratos de joint venture, o Conselho Administrativo de Defesa Econômica (CADE) editou a Súmula nº 4, com a seguinte redação:

É lícita a estipulação de cláusula de não-concorrência na vigência de joint venture, desde que guarde relação direta com seu objeto e que fique restrita aos mercados de atuação.

Pode-se concluir que a definição do limite material reside na necessidade de especificação do ramo de atividade que é desenvolvido pelo estipulante da cláusula e, assim, não poderá ser objeto de atuação pelo obrigado (NERY JR, 2014).

Nelson Nery Júnior (2014) ainda inclui no rol de requisitos a necessidade de uma contrapartida financeira pela não concorrência, proporcional ao período em que o obrigado deixará de atuar em determinado segmento de mercado.

Quanto ao elemento financeiro, o mencionado autor considera essencial a contrapartida financeira pela não competição "em contratos de toda natureza jurídica, não apenas em avenças de trabalho, posto ser medida suficiente para equilibrar a imposição de restrição à livre concorrência com a manutenção da livre iniciativa" (NERY JR, 2014, p. 9).

Todavia, esse entendimento prevalece apenas no âmbito das relações de trabalho, já que em contratos empresariais de longa duração, o fundamento da restrição de competição reside na transferência de informações, segredos e métodos que permitem o exercício de

Revista Brasileira de Direito Empresarial | e-ISSN: 2526-0235| Porto Alegre | v. 4 | n. 2 | 
atividade potencialmente lucrativa. Em um contexto de reciprocidade no contrato, a vedação de competição é a prestação negativa de uma parte, em decorrência do acesso aos segredos do negócio detidos pela outra parte.

Essa afirmação é corroborada ao analisar-se a jurisprudência sobre a matéria, considerando que vem sendo reconhecida a validade e eficácia de cláusula de não concorrência que contenha limites territorial e espacial. O Superior Tribunal de Justiça (STJ) já analisou o tema (Recurso Especial nº 1.203.109 - MG, Terceira Turma, Relator Ministro Marco Aurélio Belizze, julgado em 05.05.2015), confirmando a adequação de obrigação delimitada espacial (restrita ao local do estabelecimento utilizado para exercício da atividade) e temporalmente (seis meses), vide fundamentação exposta no voto condutor do julgado:

Nessa trilha, deve-se buscar na hipótese dos autos a finalidade pretendida pelas partes ao firmarem a cláusula sub judice para, então, compreender-se sua adequação, ou não, à autonomia privada conformada pela funcionalização do direito privado, nos termos do art. 421 do CC.

[...] no contrato sub judice a vedação contratual deu-se pelo prazo expresso de 6 (seis) meses e restrita ao local do estabelecimento utilizado para o exercício do contrato associativo. Desse modo, restrição limitada nos termos contratuais afigura-se consentânea com o potencial de causação de prejuízos à concorrência.

Em outra oportunidade (Recurso Especial no 680.815 - PR, Quarta Turma, Relator Ministro Raul Araújo julgado em 20.03.2014), o Superior Tribunal de Justiça entendeu por definir limites à cláusula de não restabelecimento inserida em contrato de compra e venda de estabelecimento, considerando como abusivo o prazo indeterminado, demonstrando que o requisito do limite temporal vem sendo exigido no caso concreto.

No âmbito do Tribunal de Justiça de São Paulo (Agravo de Instrumento $n^{\circ} 0008201$ 64.2012.8.26.0000, 2a Câmara Reservada de Direito Empresarial, Relator Desembargador Ricardo Negrão, julgado em 16.10.2012), embora tenha sido reconhecida a legalidade da cláusula de não concorrência em contrato de franquia, como instrumento de proteção de conhecimentos e técnicas específicas empregadas nas atividades empresariais, exarou-se entendimento pela necessidade de definição de limite territorial para a restrição, sob pena de desvio da razoabilidade da obrigação, nos seguintes termos:

Em regra, a orientação jurisprudencial pátria aponta para a legalidade da cláusula de não concorrência como mecanismo sujeito à disposição de 
vontade entre as partes e apto a resguardar os conhecimentos e técnicas específicas empregados no negócio empresarial, protegendo-o da concorrência desleal que possa vir a sofrer nos casos de retirada de sócio, cessação de contrato de franquia, como in casu, ou qualquer outra hipótese análoga.

No caso concreto e diante da cláusula transcrita, em que pese a cláusula de não concorrência seja medida autorizada e recomendada nos contratos de franquia (art. $3^{\circ}$, XIV, $b$, da Lei 8.955/94), deve ser reconhecido que a literalidade do conteúdo acordado revela irregularidade parcial diante do desvio da razoabilidade no que se refere à inexistência de limite territorial para a proibição, impondo seja feita ressalva neste aspecto.

Portanto, ainda que a cláusula de não competição seja admitida em contratos empresariais de longa duração e tenha como função a proteção de interesses legítimos, a adequação da cláusula e consequente reconhecimento da sua validade e eficácia dependem do preenchimento de certos requisitos que evitam o excesso e a disfunção da obrigação.

\section{EFICÁCIA DO DEVER E DA CLÁUSULA DE NÃO COMPETIÇÃO}

Aspecto também essencial no estudo da não competição reside na questão da eficácia, enquanto dever oriundo da boa-fé objetiva e como obrigação contratual expressamente pactuada.

A obrigação de não competir tem como função evitar a prática de concorrência desleal e o desvio de clientela, ou mesmo garantir a satisfação dos interesses contratuais, após a extinção do contrato. ${ }^{14}$

Nesse contexto, a cláusula de não competição gera efeitos para além da vigência do contrato, o que seria caso da chamada pós-eficácia continuada, conforme conceituação apresentada por Antônio Manuel da Rocha e Menezes Cordeiro (2001), pois ainda que a obrigação principal do contrato se extinga, subsiste a obrigação de não competir.

O fato de a cláusula gerar efeitos para além da vigência contratual guarda relação direta com a sua funcionalidade.

\footnotetext{
${ }^{14}$ Mesmo depois de finda uma situação obrigacional, persiste o dever de não adotar condutas que possam frustrar o contrato, reduzir as vantagens da contraparte ou até mesmo causar-lhe dano, sendo uma dessas hipóteses, "de grande relevo econômico [...] o dever de não concorrência." (MENEZES CORDEIRO, 2001, p. 629).
}

Revista Brasileira de Direito Empresarial | e-ISSN: 2526-0235| Porto Alegre | v. 4 | n. 2 |

p. $20-38$ | Jul/Dez. 2018 
Isto é o que depreende-se do posicionamento do Superior Tribunal de Justiça, no já citado Recurso Especial $\mathrm{n}^{\circ}$ 1.203.109 - MG, quando a Corte Superior reconheceu que a resolução do vínculo contratual não afasta a eficácia da cláusula de não concorrência, justamente a fim de preservar a própria funcionalidade da cláusula, conforme excerto transcrito a seguir:

[...] Por fim, deve também ser afastada a conclusão do acórdão recorrido no sentido de que, resolvido o vínculo contratual do credenciamento, não teria qualquer eficácia a cláusula sub judice. Primeiramente, esse entendimento retira da cláusula toda sua funcionalidade, existente, como demonstrado, na medida em que protege o ambiente concorrencial de distorções indesejadas. $[\ldots]$

O descumprimento da restrição à competição pelo obrigado permite ao estipulante promover a execução específica da obrigação de não fazer (art. 822 do Código de Processo Civil $^{15}$ ), assim como postular indenização à vista da responsabilidade decorrente do inadimplemento da obrigação que produz efeitos pós-negociais. (BEZERRA JÚNIOR, 2014).

Já o dever de não competição e sua natureza autônoma e prospectiva podem ser explicados pela doutrina de Clóvis do Couto e Silva (2016) sobre os deveres anexos independentes. Segundo o citado autor, alguns deveres são suscetíveis de ultrapassar o término da obrigação principal e terem vida própria. Dependem da obrigação principal para nascer, mas podem ser acionados independentemente daquela. Eles são autônomos, pois têm um fim próprio, independente do fim da obrigação principal (COUTO E SILVA, 2006).

O autor português Mário Júlio de Almeida Costa (1998), ao tratar dos efeitos que os contratos podem produzir depois de se extinguirem, cunhou o conceito de eficácia posterior das obrigações.

O contexto no qual se admite uma eficácia do contrato posterior ao seu término ocorre quando a "completa satisfação dos interesses das partes pode determinar que esses deveres principais de prestação sejam acompanhados por deveres secundários e por deveres laterais" (COSTA, 1998, p. 305).

Assim, ainda que as obrigações de prestação contratuais tenham sido cumpridas, aos contratantes são impostos deveres vedando comportamentos capazes de prejudicar o fim do

\footnotetext{
${ }^{15}$ Art. 822. Se o executado praticou ato a cuja abstenção estava obrigado por lei ou por contrato, o exequente requererá ao juiz que assine prazo ao executado para desfazê-lo.
}

Revista Brasileira de Direito Empresarial | e-ISSN: 2526-0235| Porto Alegre | v. 4 | n. 2 |

p. $20-38$ | Jul/Dez. 2018 
contrato, que resultam na possibilidade de surgimento do dever de indenizar decorrente de conduta da parte após o término do contrato (COSTA, 1998).

Como explica Menezes Cordeiro (2001, p. 630), o "escopo contratual não pode ser frustrado a pretexto de que a obrigação se extinguiu". Depois de extinta a relação contratual, alguns deveres subsistiriam para as partes e, na hipótese de descumprimento, dão origem a um dever de indenizar, pela denominada culpa post factum finitum (MENEZES CORDEIRO, 2001).

Dessa forma, ainda que não haja obrigação específica instrumentalizada em contrato, em algumas relações a própria natureza do negócio gera o dever de não competir, cuja eficácia opera além da extinção do contrato e funciona como meio de resguardar a satisfação integral das partes e desencorajar condutas que podem prejudicar o fim do contrato.

\section{CONSIDERAÇÕES FINAIS}

Através deste artigo se propôs o estudo da não competição no âmbito dos contratos empresariais de longa duração, tanto como obrigação contratual expressamente pactuada, quanto como dever decorrente da boa-fé objetiva.

A estrutura da relação obrigacional complexa e o conceito de obrigação como processo, no qual o vínculo obrigacional é concebido como uma ordem de cooperação polarizada pelo adimplemento, possuem fundamental importância para o reconhecimento de que a estrutura do contrato identifica a origem do dever de não competição e seu fundamento.

Existem contratos cuja natureza permite o esvaziamento por prática posterior de um dos contratantes. Nesses casos, há um dever de não competição, que ultrapassa o término da obrigação principal e tem vida própria.

Por outro lado, se a própria natureza do contrato não permite identificar o nascimento do dever de não competir, faz-se necessária a expressa previsão contratual, com a finalidade de impor obrigação negativa à contraparte.

Por se tratar de obrigação negativa que gera restrição à livre iniciativa da parte obrigada, a estipulação da obrigação deve conter certos limites, sob pena de reconhecimento

Revista Brasileira de Direito Empresarial | e-ISSN: 2526-0235| Porto Alegre | v. 4 | n. 2 |

p. $20-38$ | Jul/Dez. 2018 
de excesso e disfunção. Desse efeito, verificou-se que a obrigação deve servir para proteger interesse legítimo do estipulante, além de conter limitações de ordem temporal, territorial e material.

A obrigação de não competir possui eficácia pós-contratual e protege o estipulante para além da conclusão do contrato, servindo tanto para fins impeditivos (obrigação de não fazer) quanto para fins indenizatórios (perdas e danos), na hipótese de descumprimento da parte obrigada.

Nos contratos onde há um dever de não concorrência por força da própria natureza do negócio, como elemento necessário para que as partes se abstenham de realizar condutas que esvaziem o pacto, o eventual descumprimento do dever se traduz no surgimento de uma responsabilidade pós-contratual (culpa post pactum finitum).

Portanto, a não competição, que incide de forma ulterior à extinção do contrato, caracteriza-se como uma importante condição para proteção de interesses legítimos e para garantia da completa satisfação das partes contratantes no âmbito dos contratos de longa duração.

\section{REFERÊNCIAS BIBLIOGRÁFICAS}

BEZERRA JUNIOR, Luis Martius Holanda. O contrato de franquia e a violação dos deveres anexos de conduta: a boa-fé como fronteira de atuação das partes (da culpa in contrahendo à culpa post factum finitum). In: RIDB - Revista do Instituto de Direito Brasileiro. Lisboa, ano 3 (2014), n. 9, p. $6465-6536$.

BRANCO, Gerson Luiz Carlos. Função social dos contratos. Interpretação à luz do Código Civil. In: MARTINS-COSTA, Judith. Modelos de direito privado. São Paulo: Marcial Pons, 2014, p. 268.

BRASIL. Conselho Administrativo de Defesa Econômica. Ato de Concentração 08012.009679/2007-50. Relator Conselheiro Olavo Zago Chinaglia. Parecer do procurador federal Diogo Thomson de Andrade. p. 393 - 400.

BRASIL. Superior Tribunal de Justiça. Recurso Especial nº 680.815 - PR, Quarta Turma, Relator Ministro Raul Araújo, Brasília, julgado em 20.03.2014, publicado no DJe em 03.02.2015. 
BRASIL. Superior Tribunal de Justiça. Recurso Especial no 1.203.109 - MG, Terceira Turma, Relator Ministro Marco Aurélio Belizze, Brasília, julgado em 05.05.2015, publicado no DJe em 11.05.2015.

BRASIL. Tribunal de Justiça do Estado de São Paulo. Agravo de Instrumento $\mathrm{n}^{\circ} 0008201$ 64.2012.8.26.0000, 2 ${ }^{\mathrm{a}}$ Câmara Reservada de Direito Empresarial, Relator Desembargador Ricardo Negrão, São Paulo, julgado em 16.10.2012, publicado no Diário de Justiça Eletrônico em 19.10.2012.

COSTA, Mário Júlio de Almeida. Direito das obrigações. $7^{\text {a }}$ ed. Coimbra: Almedina, 1998.

COUTO E SILVA, Clóvis V. A obrigação como processo. Rio de Janeiro: Editora FGV, 2006.

DANCE, Jess A.; SENTELL, William W. Turning an (Occasional) Blind Eye: Selective Enforcement of Franchisee Post-Term Non-Compete Covenants. In: Franchise Law Journal. vol. 37, n. $\quad$ 2, Fall/2017. Disponível em: <https://www.americanbar.org/content/dam/aba/publications/franchising_law_journal/Fall201 7/FLJ\%2037-2_04Dance-Sentell.authcheckdam.pdf> Acesso em: 21 jun. 2018.

FÉRES, Marcelo Andrade. Cláusula (legal) de interdição da concorrência no trespasse do estabelecimento comercial. Disponível em <https://pos.direito.ufmg.br/rbep/index.php/rbep/article/viewFile/120/116>. Acesso em: 11 jul. 2018.

FORGIONI, Paula A. Contrato de distribuição. $2^{\text {a }}$ ed. São Paulo: Editora Revista dos Tribunais, 2008.

Contratos empresariais: teoria geral e aplicação. 3. ed. ver., atual. e ampl. São Paulo: Revista dos Tribunais, 2018.

Malheiros, 2005.

; GRAU, Eros Roberto. O estado, a empresa e o contrato. São Paulo:

FRANCO, Vera Helena de Mello. Contratos: direito civil e empresarial. $5^{\mathrm{a}}$ ed. rev. atual. e ampl. São Paulo: Editora Revista dos Tribunais, 2014.

GARCIA, Rodrigo Saraiva Porto; SANT'ANNA, Leonardo da Silva. A cláusula de não concorrência nos contratos de franquia: considerações acerca da função social do contrato e da boa-fé objetiva. In: Revista de Direito Privado. v. 84/2017, p. 51-83, Dez/2017.

GOMES, Orlando. Obrigações. 13ª ed. rev. atual. Rio de Janeiro: Forense, 2000.

MARTINS-COSTA, Judith. Modelos de direito privado. São Paulo: Marcial Pons, 2014.

MENEZES CORDEIRO, Antônio Manuel da Rocha e. Da boa fé no direito civil. Porto: Almedina, 2001.

Revista Brasileira de Direito Empresarial | e-ISSN: 2526-0235| Porto Alegre | v. 4 | n. 2 |

p. $20-38$ | Jul/Dez. 2018 
NAVAS, Amanda R. E. Análise in casu das cláusulas de não concorrência em contratos de distribuição. In: Revista dos Tribunais, vol. 929/2013, p. 1209 - 1246, Mar / 2013, DTR $2013 \backslash 588$.

NERY JR., Nelson. Cláusula de não concorrência e seus requisitos - prejudicialidade externa entre processos. In: Soluções Práticas de Direito - Nelson Nery Junior. vol. 7/2014, p. 467 513 , Set / 2014.

OPPO, Giorgio. I contratti di durata. In: Revista di Diritto Commerciale, 1943, p. 143-250.

PIRAJÁ, André Bedin; CANESIN, Maria Eugência. A cláusula de não concorrência comercial nos contratos de franquia. In: Revista de Direito Empresarial, vol. 7/2015, p. 37 51, Jan - Fev / 2015, DTR 2015\1407.

SANTOS, Alexandre David. Aplicabilidade e limites das cláusulas de não concorrência nos contratos de franquia. Dissertação de mestrado. Escola de Direito da Fundação Getúlio Vargas, São Paulo, 2016.

WALD, Arnoldo; XAVIER, Alberto. Pacto de não concorrência - validade e seus efeitos no direito brasileiro. In: Doutrinas Essenciais de Direito Empresarial, vol. 2, p. 847 - 863, Dez / 2010, DTR\2012\1839. 